\title{
Arterial oxygen tension and response to oxygen breathing in differential diagnosis of congenital heart disease in infancy
}

\author{
R. W. A. JONES*, J. H. BAUMER†, M. C. JOSEPH, and ELLIOT A. SHINEBOURNE \\ From the Department of Paediatric Cardiology, Brompton Hospital, London
}

Jones, R. W. A., Baumer, J. H., Joseph, M. C., and Shinebourne, E. A. (1976). Archives of Disease in Childhood, 51, 667. Arterial oxygen tension and response to oxygen breathing in differential diagnosis of congenital heart disease in infancy. Arterial oxygen tension was measured from radial artery samples in 276 infants referred for cardiological investigation. Values obtained during air breathing in infants with congenital heart disease showed considerable overlap between 'cyanotic' and 'acyanotic' groups, and are of limited diagnostic use. By contrast, values obtained while breathing oxygen in concentrations of over $80 \%$, measured in 182 ininfants, allowed clear differentiation between these groups. All infants with acyanotic, but only 2 of 109 with cyanotic lesions, achieved an arterial oxygen tension of more than $150 \mathrm{mmHg}$. In the cyanotic group the response to oxygen breathing was significantly greater in common mixing situations and in the hypoplastic left heart syndrome than with either pulmonary outflow tract obstruction or transposition of the great arteries. Infants with transposition had a significantly lower mean arterial oxygen tension in air than infants with other forms of cyanotic congenital heart disease.

Of 23 infants whose final diagnosis was primary lung disease but in whom cyanotic congenital heart disease had been suspected, 7 achieved arterial oxygen tensions of more than $150 \mathrm{mmHg}$ during oxygen breathing, and on this basis cardiac catheterization was not performed. We therefore conclude that measurement of the arterial oxygen tension while breathing high concentrations of oxygen should be routinely performed in the initial assessment of sick infants with suspected congenital heart disease.

\section{Abbreviations}

CMS: common mixing situation

HLHS: hypoplastic left heart syndrome

$\mathrm{PaO}_{2}$ arterial oxygen tension

PDA: persistent ductus arteriosus

POTO: pulmonary outflow tract obstruction

RDS: respiratory distress syndrome

TGA: transposition of great arteries

The division of patients with congenital heart disease into 'cyanotic' and 'acyanotic' groups forms the basis of most attempts to classify this diverse

\footnotetext{
Received 2 January 1976.

Present addresses: *The Hospital for Sick Children, Great Ormond Street, London WC1.

†Freedom Fields Hospital, Greenbank Terrace, Plymouth.
}

group of anomalies (Wood, 1956; Perloff, 1970). In the individual case, however, even this basic distinction may sometimes be difficult to make without resort to cardiac catheterization. Clinical assessment of arterial saturation is inaccurate (Comroe and Botelho, 1947; Goldman et al., 1973), and many forms of cyanotic congenital heart disease with right to left shunt but increased pulmonary flow may achieve oxygen saturations above the level at which cyanosis becomes detectable. In addition, infants with acyanotic lesions may become cyanosed when heart failure or chest infection are present, and primary lung disease may mimic cyanotic congenital heart disease, especially in the neonatal period (Roberton, Hallidie-Smith, and Davis, 1967).

We have found that measurement of $\mathrm{PaO}_{2}$ in high oxygen concentrations is extremely useful, both in 
helping to delineate those infants with cyanotic congenital heart disease, and in the differential diagnosis of the individual lesion. Though other workers have stated this (Lees, 1970; Nadas and Fyler, 1972), no large series of infants has been reported where the clinical validity of this simple test has been assessed. This paper analyses our results in a large number of symptomatic infants referred with suspected congenital heart disease.

\section{Patients and methods}

386 infants under one year of age were admitted to Brompton Hospital between January 1973 and February 1975, with a provisional diagnosis of heart disease. Records were available for 384 . Of these, 63 had arterial blood gases estimated while breathing air alone, and 182 had blood gases estimated while breathing high oxygen concentrations; in 154 of the latter blood gases were also estimated in air (Table I).

Blood gases were estimated in all infants from samples obtained by radial artery puncture. No record was made of whether the infants were crying. Samples were withdrawn anaerobically into $1 \mathrm{ml}$ plastic syringes, the dead space of which had been filled with heparin 1000 units $/ \mathrm{ml}$, and refrigerated until analysis (within one hour of arterial puncture). $\mathrm{PaO}_{2}$ was measured using the Corning 165 Blood Gas Analyser (Biomedical Engineering). $\quad p \mathrm{H}$ and $\mathrm{PaCO}_{2}$ were also measured.

Inspired oxygen concentrations of between $80 \%$ and $95 \%$ were obtained by using a Perspex head box (Warley and Gairdner, 1962) in 178 infants. 4 infants were intubated and required intermittent postive pressure ventilation, and in these the oxygen was delivered via the ventilator. High oxygen concentrations were administered for a minimum of 10 minutes before arterial blood sampling and were continued during the procedure.

A complete anatomical diagnosis was obtained from cardiac catheterization and angiography, supplemented by post-mortem examination when this was performed. Information from these sources was available in $92 \%$ of infants with heart disease. Of the remaining $8 \%$, all but one was thought to have acyanotic heart disease not requiring cardiac catheterization. The remaining infant died before further investigation and necropsy was not performed.

\section{Results}

Patients. Infants were divided into groups of those with cyanotic and those with acyanotic heart disease. For the two groups, $\mathrm{PaO}_{2}$ in air and in high oxygen concentrations, as well as the rise in $\mathrm{PaO}_{2}$ with change in inspired oxygen concentration $\left(\mathrm{PaO}_{2}\right.$ in oxygen minus $\mathrm{PaO}_{2}$ in air), were compared. Infants with cyanotic congenital heart disease were divided into diagnostic categories and $\mathrm{PaO}_{2}$ was likewise compared between the groups. Statistical significance was assessed by using the unpaired ' $t$ ' test.

Arterial blood gases were analysed in $72 \%$ of infants in the study (Table I). In those under one week of age blood gases were analysed in $87 \%$ (87 out of 99), whereas in the older infants (those aged 1 month to 1 year) blood gas analyses were thought at the time to be clinically indicated in only $57 \%$ (103 out of 179).

Cyanotic and acyanotic congenital heart disease. 31 of the 276 infants with blood gas data were excluded as the inspired oxygen concentration at the time of blood sampling was not stated. The mean $\mathrm{PaO}_{2}$ in air of infants with cyanotic congenital heart disease was $39 \mathrm{mmHg}$, and in oxygen $54 \mathrm{mmHg}$. In infants with acyanotic heart disease mean $\mathrm{PaO}_{2}$ in air was $73 \mathrm{mmHg}$ and in oxygen $268 \mathrm{mmHg}$. Though the mean $\mathrm{PaO}_{2}$ in air was significantly different $(P<0.001)$ between the two groups, the overlap between them did not allow discrimination between cyanotic and acyaanotic heart disease in the majority $(68 \%)$ of infants (Fig. 1).

In high oxygen concentrations, however, $\mathrm{PaO}_{2}$ was highly discriminating between the two groups (Fig. 2). None of the group with acyanotic heart disease had a $\mathrm{PaO}_{2}$ of less than $150 \mathrm{mmHg}$, while

TABLE I

Proportion of infants under study in whom blood gases were analysed

\begin{tabular}{|c|c|c|c|c|}
\hline & \multicolumn{4}{|c|}{ Age } \\
\hline & $<1$ week & $\begin{array}{l}1 \text { week to } \\
1 \text { month }\end{array}$ & $\begin{array}{l}1 \text { month to } \\
1 \text { year }\end{array}$ & $\begin{array}{c}\text { All } \\
\text { patients }\end{array}$ \\
\hline $\begin{array}{l}\text { Total no. of patients } \\
\text { Blood gases in air and oxygen } \\
\text { Blood gases in oxygen alone } \\
\text { Blood gases in air alone } \\
\text { Blood gases: inspired oxygen } \\
\text { concentration not stated } \\
\text { Blood gases not analysed }\end{array}$ & $\begin{array}{r}99 \\
54 \\
10 \\
16 \\
7 \\
72\end{array}$ & $\begin{array}{r}106 \\
53 \\
7 \\
19 \\
\\
7 \\
20\end{array}$ & $\begin{array}{r}179 \\
47 \\
11 \\
28 \\
\\
17 \\
76\end{array}$ & $\begin{array}{r}384 \\
154 \\
28 \\
63 \\
\\
31 \\
108\end{array}$ \\
\hline
\end{tabular}




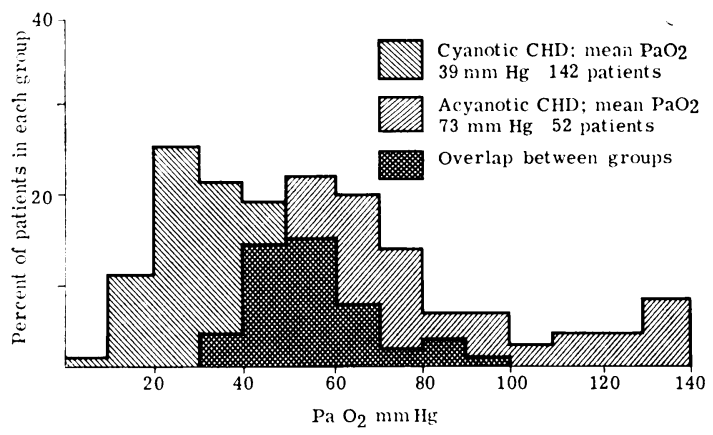

FIG. 1.-Comparison of $\mathrm{PaO}_{2}$ in air between infants with cyanotic and acyanotic congenital heart disease. Area of overlap between the two groups is from 30 to $100 \mathrm{mmHg}$. $68 \%$ of infants have $\mathrm{PaO}_{2}$ values within this range, and in the majority discrimination between cyanotic and acyanotic heart disease is not possible.

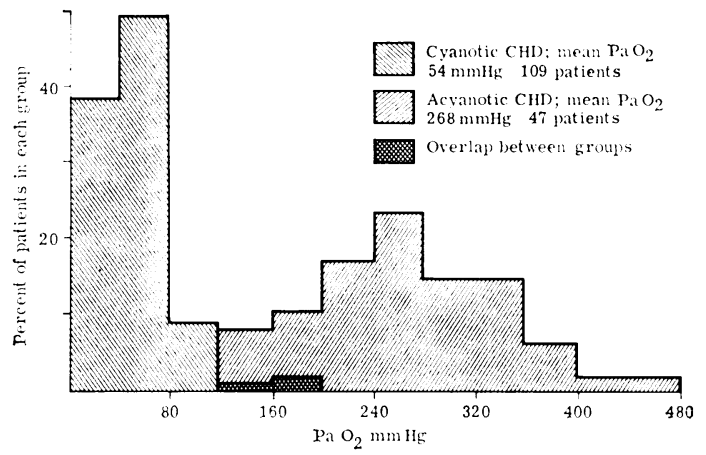

Fig. 2.-Comparison of $\mathrm{PaO}_{2}$ in high oxygen concentrations between infants with cyanotic and acyanotic congenital heart disease. Overlap between the groups is such that only 2 infants with cyanotic heart disease had values $>150 \mathrm{mmHg}$.

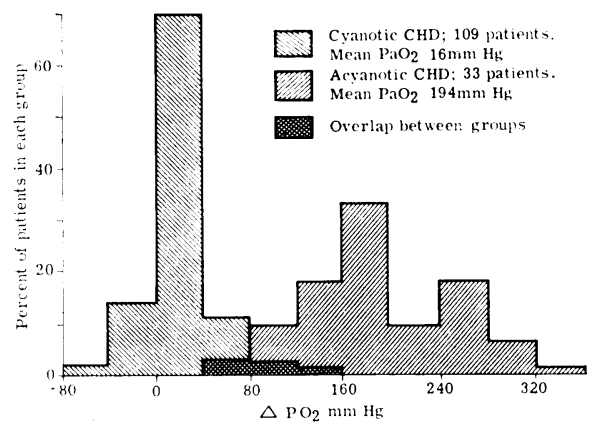

FIG. 3.-Rise in $\mathrm{PaO}_{2}\left(\triangle \mathrm{PO}_{2}\right)$ on breathing high oxygen concentrations compared with $\mathrm{PaO}_{2}$ on breathing room air. Values are shown for infants with cyanotic and acyanotic congenital heart disease. Overlap between the groups is shown. only 2 infants with cyanotic congenital heart disease had $\mathrm{PaO}_{2}$ values of more than $150 \mathrm{mmHg}$ (both had CMS and high pulmonary blood flows). The rise in $\mathrm{PaO}_{2}$ (Fig. 3) also clearly distinguished the two groups but gave no better discrimination between them than did $\mathrm{PaO}_{2}$ in high inspired oxygen concentrations.

Infants with primary lung disorders. 23 infants referred with suspected cyanotic congenital heart disease were subsequently shown to have primary lung disorders. In $7 \mathrm{PaO}_{2}$ in high oxygen concentrations rose above $150 \mathrm{mmHg}$ and on this basis cyanotic congenital heart disease was excluded. 3 of the remainder had localized $x$-ray changes of pneumonia; one of these had a $\mathrm{PaO}_{2}$ of $100 \mathrm{mmHg}$ in oxygen, which would not rule out cyanotic congenital heart disease.

Eleven of the remaining 13 infants underwent cardiac catheterization and all showed evidence of a right to left shunt via a PDA. A patent foramen ovale was shown in all infants catheterized, through which right to left shunting was found in 5. Pulmonary venous desaturation, despite high inspired oxygen concentrations, was shown in the remainder. The last two neonates (whose $\mathrm{PaO}_{2}$ did not rise above $150 \mathrm{mmHg}$ with high inspired oxygen concentrations) were not subjected to cardiac catheterization as they were thought clinically to have unequivocal severe hyaline membrane disease.

Infants with cyanotic congenital heart disease. These infants were divided into diagnostic categories according to the haemodynamic situation producing cyanosis. Four different groups were recognized.

(1) Complete TGA. (2) POTO; the anomalies listed in Table II were included in this group, all of which are characterized by shunting of blood away from the lungs. (3) CMS; the anomalies listed in Table III were included in this group. In

TABLE II

Anomalies resulting in POTO and cyanosis

Fallot's tetralogy

Primitive ventricle + pulmonary stenosis or pulmonary atresia

Pulmonary atresia \pm ventricular septal defect

Tricuspid atresia \pm small ventricular septal defect

Pulmonary stenosis + patent foramen ovale

Double outlet right ventricle + pulmonary stenosis

Hypoplastic right ventricle

Corrected transposition + pulmonary stenosis + ventricular septal defect

Total (blood gases done in 55) 65 
TABLE III

\section{Anomalies producing CMS}

Total anomalous pulmonary venous drainage

Tricuspid atresia + large ventricular septal defect

Truncus arteriosius type I

Double outlet right ventricle

Primitive ventricle

Primitive ventricle + coarctation

Primitive ventricle + single atrium

Double outlet right ventricle + coarctation

Primitive ventricle + mitral atresia

Total (blood gases done in 33)

this group are included those anomalies where admixed systemic and pulmonary venous blood is distributed to both great arteries. (4) HLHS.

The mean $\mathrm{PaO}_{2}$ of the different groups was compared in air and oxygen; the rise in $\mathrm{PaO}_{2}$ in response to rise in inspired oxygen concentration was also compared (Fig. 4, Table IV). In air the

\section{TABLE IV}

Comparison between different groups with cyanotic congenital heart disease

\begin{tabular}{l|c|c|c}
\hline & \multicolumn{2}{|c}{ P values } & \\
\cline { 2 - 3 } & \multicolumn{1}{|c|}{ Air } & Oxygen & Rise \\
\hline TGA/POTO & $<0.02$ & NS & NS \\
POTO/CMS & NS & $<0.01$ & NS \\
CMS/HLHS & NS & NS & NS \\
TGA/CMS & $<0.01$ & $<0.001$ & $<0.05$ \\
POTO/HLHS & NS & $<0.001$ & $<0.01$ \\
TGA/HLHS & $<0.001$ & $<0.001$ & $<0.001$ \\
& & & \\
\hline
\end{tabular}

NS, not significant.

mean $\mathrm{PaO}_{2}$ was significantly higher in infants with POTO (39 $\mathrm{mmHg}$ ), CMS (42 $\mathrm{mmHg}$ ), and HLHS $(47 \mathrm{mmHg}$ ) than in those with TGA (30 mmHg). In oxygen the mean $\mathrm{PaO}_{2}$ was significantly higher in infants with CMS (64 $\mathrm{mmHg}$ ) and HLHS (79 $\mathrm{mmHg}$ ) than in those with TGA (39 $\mathrm{mmHg}$ ) and POTO $(45 \mathrm{mmHg})$. Mean $\mathrm{PaO}_{2}$ rise in infants with CMS (21 $\mathrm{mmHg}$ ) and HLHS $(36 \mathrm{mmHg}$ ) was significantly greater than in infants with TGA (9 $\mathrm{mmHg}$ ); the mean $\mathrm{PaO}_{2}$ rise in infants with HLHS was significantly greater than in those with POTO $(12 \mathrm{mmHg})$. There was no significant difference in mean $\mathrm{PaO}_{2}$ between infants with common mixing situations and those with HLHS.

In infants with TGA comparison was made between those with a ventricular septal defect and those with intact ventricular septum. In air the mean $\mathrm{PaO}_{2}$ of the former $(39 \mathrm{mmHg}$ ) was significantly higher than of the latter $(25 \mathrm{mmHg})(P<0.02)$.
However, there was no significant difference between the groups in high inspired oxygen concentrations, nor in their response to changes in inspired oxygen concentration.

Infants with TGA were also divided into those with and those without a PDA as shown at cardiac catherization. No significant differences were shown.

\section{Discussion}

The spectrum of congenital heart disease seen was comparable to that in other series (Lambert, Canent, and Hohn, 1966; Rowe and Mehrizi, 1968; Campbell, 1973), and is representative of symptomatic infants referred to a specialist centre for investigation. This study was undertaken to ascertain whether measurement of $\mathrm{PaO}_{2}$ and its response to high oxygen concentrations would provide clinical information in the initial assessment of these infants. $\mathrm{PaO}_{2}$ in oxygen proved to be far more useful than measurement in air, allowing clear differentiation between cyanotic and acyanotic groups, and in the former providing useful clues to the type of congenital defect present. The extent of the rise in $\mathrm{PaO}_{2}$ after oxygen administration gave no additional information. In 7 infants referred with suspected cyanotic congenital heart disease, the values for $\mathrm{PaO}_{2}$ in oxygen supported our clinical diagnosis of primary lung disease, thereby obviating the need for cardiac catheterization.

Under the conditions of the present study, we have found that $\mathrm{a}^{\mathrm{PaO}_{2}}$ of $150 \mathrm{mmHg}$ while breathing oxygen in concentrations of over $80 \%$ provides a convenient 'watershed' separating cyanotic from acyanotic congenital heart disease (Fig. 2). In practice, few infants with cyanotic lesions achieved $\mathrm{PaO}_{2}$ values of more than $100 \mathrm{mgHg}$, and most infants with acyanotic lesions achieved values far greater than $150 \mathrm{mmHg}$. The latter would be expected on theoretical grounds, for by use of the shunt equation relating alveolar to arterial oxygen tension (Strang and Macleish, 1961), it can be calculated that $\mathrm{PaO}_{2}$ of $150 \mathrm{mmHg}$ in $80 \%$ oxygen corresponds to a right to left shunt of approximately $25 \%$ of the cardiac output. However, intrapulmonary shunts of this size may occur in normal newborn infants (Nelson et al., 1963), and in those with acyanotic congenital heart disease and increased pulmonary flow (Lees, Way, and Ross, 1967). In addition, the crying often induced by arterial puncture may produce intracardiac right to left shunting (Prec and Cassels, 1952). These factors may explain why several infants with acyanotic lesions failed to achieve $\mathrm{PaO}_{2}$ values of more than 150-200 mmHg. 
In cyanotic congenital heart disease arterial desaturation may be due to several different mechanisms, each depending on the haemodynamic situation present. Thus, in the present study, infants have been grouped according to the haemodynamic rather than anatomical defect present. In air, those with TGA, the commonest cyanotic lesion in the series, had a mean $\mathrm{PaO}_{2}$ value significantly lower than in any other form of cyanotic congenital heart disease. Since arterial desaturation in TGA is due to inadequate mixing of pulmonary and systemic circulations, those infants with additional ventricular septal defect would be expected to have higher values than those with intact ventricular septum. In our series this difference was significant only during air breathing. Similarly no difference could be shown for infants with TGA with or without PDA.

Whereas other workers have stated that in cyanotic congenital heart disease $\mathrm{PaO}_{2}$ is unlikely to rise above $100 \mathrm{mmHg}$ while breathing pure oxygen (Liebman and Whitman, 1973; Lees, 1973), we have found that this occurred in 8 of the 109 infants studied. The maximum values during oxygen breathing were seen in infants with CMS and HLHS (Fig. 4), and may be explained by the high effective pulmonary blood flow (the proportion of the systemic venous return that is theoretically fully oxygenated by passage through the lungs) in these conditions, this being maximal when pulmonary vascular resistance falls in response to

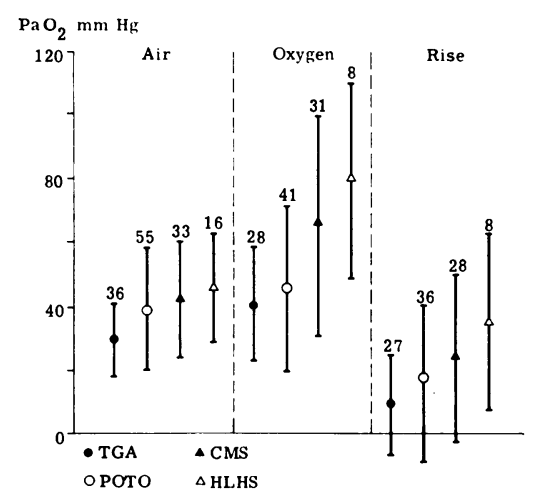

Fig. 4.-Comparison of $\mathrm{PaO}_{2}$ between groups of infants with cyanotic congenital heart disease. Mean and SD are shown for patientswith TGA,POTO,CMS, and HLHS. Values are shown while infants breath room air and high inspired oxygen concentrations. In the last column are values for the rise in $\mathrm{PaO}_{2}$ in each group. Numbers above individual values indicate the number of patients in each group. Significance of differences between groups is given in Table IV. oxygen administration. It is notable that the only 2 of 109 infants with cyanotic congenital heart disease who achieved $\mathrm{PaO}_{2}$ values of more than $150 \mathrm{mmHg}$ during oxygen breathing belonged to the CMS group. One infant had a primitive ventricle, the other a persistent truncus arteriosus. In addition to a high effective pulmonary blood flow, preferential 'streaming' of saturated and unsaturated blood in the common mixing chamber resulting in higher oxygen saturations in the aorta than the pulmonary artery, has been shown in both these conditions (Tandon, Hauck, and Nadas, 1963; Rahimtoola, Ongley, and Swan, 1966), and may explain the high values in these 2 infants.

In contrast to the haemodynamic situation in CMS, total and effective pulmonary blood flow in POTO is reduced (the chest $x$-ray showing oligaemia rather than plethora). In addition, obstruction to ventricular outflow is relatively fixed, and pulmonary flow does not increase in response to oxygen administration. Thus $\mathrm{PaO}_{2}$ values rose only minimally (Fig. 4), and may indeed fall in some cases, perhaps due to constriction of a PDA which is contributing to pulmonary flow.

HLHS usually results in severe heart failure and low cardiac output in early infancy (Noonan and Nadas, 1958), and has been considered separately because of this characteristic presentation. Differentiation from heart failure due to acyanotic congenital heart disease, and from other causes of shock such as sepsis or haemorrhage, is aided by measurement of the $\mathrm{PaO}_{2}$ in high oxygen concentrations. Though the highest mean $\mathrm{PaO}_{2}$ values were seen in this group (Fig. 4), in none did this exceed $150 \mathrm{mmHg}$. HLHS might also be considered as an example of common mixing, since this usually occurs at atrial level, and the $\mathrm{PaO}_{2}$ values in oxygen did not differ significantly between these two groups.

In infants with cyanotic congenital heart disease statistically significant differences between mean $\mathrm{PaO}_{2}$ values in different haemodynamic subgroups has been shown. The degree of overlap between these groups (Fig. 4) means that in the individual case clear differentiation cannot be made. However, when considered together with the clinical, chest $x$-ray, and electrocardiographic findings, useful information is obtained.

In infants with acyanotic congenital heart disease cyanosis may occur when heart failure or chest infection are present, and is due principally to alveolar hypoventilation as indicated by a raised $\mathrm{PaCO}_{2}$ (Talner et al., 1965), though intrapulmonary right to left shunting may also occur in infants with 
increased pulmonary flow (Lees et al., 1967). Differentiation from cyanotic congenital heart disease, particularly CMS, may be difficult since cyanosis in CMS is often minimal during air breathing and is abolished by oxygen administration. Furthermore, the chest $x$-ray may show cardiomegaly and pulmonary plethora in both groups. Measurement of $\mathrm{PaO}_{2}$ in oxygen, however, allows differentiation in the majority of cases. In the present series all infants with acyanotic lesions, but only 2 of 31 with CMS, achieved values of more than $150 \mathrm{mmHg}$.

Primary lung disease may cause cyanosis due to alveolar hypoventilation, impaired gas diffusion, inequalities of ventilation, and perfusion (the most extreme example of which is the perfusion of totally unventilated alveoli), or extrapulmonary right to left shunting. In respiratory distress syndrome right to left shunts of up to $80 \%$ of the cardiac output may occur (Strang and Macleish, 1961) and cyanotic congenital heart disease may be mimicked, though the clinical and radiological findings usually allow differentiation between the two. The use of a positive end expiratory pressure in addition to oxygen breathing has been reported to be helpful in distinguishing infants with primary lung disease from those with cyanotic congenital heart disease, the $\mathrm{PaO}_{2}$ rising in the former but falling in the latter group (Shannon et al., 1972). Tooley and Stanger (1972) have pointed out the limitations of this test, infants with HLHS often raising their $\mathrm{PaO}_{2}$ after addition of a positive end expiratory pressure, and infants with persistent pulmonary vascular obstruction showing no response. In the respiratory distress syndrome early measurement of $\mathrm{PaO}_{2}$ in $100 \%$ oxygen has been suggested as a guide to prognosis (Boston, Geller, and Smith, 1966), and $\mathrm{a} \mathrm{PaO}_{2}$ of more than $150 \mathrm{mmHg}$ may later help to exclude cyanotic congenital heart disease if this is subsequently suspected on clinical grounds.

When cyanosis in lung disease is due to extrapulmonary right to left shunting, this may occur via a PDA or patent foramen ovale. In these instances it is secondary to the raised pulmonary vascular resistance accompanying hypoxia, hypoventilation, or acidosis. This 'persistence of the fetal circulation' may occur in atypical respiratory distress syndrome (Roberton et al., 1967) and also be secondary to hyperviscocity, hypoglycaemia, or persistent pulmonary vascular obstruction of unknown cause (Burnell et al., 1972; Gersony, 1973; Brown and Pickering, 1974). In these circumstances the administration of high inspired oxygen concentrations ensures that the oxygen saturation of the pulmonary venous return is above $95 \%$. If right to left shunting is solely via a PDA, right radial (but not femoral or umbilical) artery samples will also be fully saturated.* Conversely, if shunting is through a patent foramen ovale, radial artery samples will be desaturated, and differentiation of primary lung disease from cyanotic congenital heart disease will not be possible on $\mathrm{PaO}_{2}$ measurement. In this group the clinical, radiological, and electrocardiographic findings may also not permit differentiation. Thus, in our experience there will be a group of infants in whom cardiac catheterization offers the only means of excluding cyanotic congenital heart disease. In a specialized unit this must be recognized and accepted since the risks of cardiac catheterization in such a unit are low, a recent report from this hospital indicating a mortality of $1.7 \%$ in the first week of life (Miller, 1974).

A fall in $\mathrm{PaO}_{2}$ after oxygen administration was seen in 16 infants with cyanotic congenital heart disease; all but one had POTO or TGA where a PDA might have contributed significantly to pulmonary flow and may have been constricted by the administration of oxygen. An alternative explanation is that of alveolar collapse secondary to 'washout' of alveolar nitrogen. Though these are theoretical hazards to the diagnostic administration of high oxygen concentrations, we have not found any infant whose condition has deteriorated as a result of the test.

In conclusion, we state that measurement of the $\mathrm{PaO}_{2}$ during administration of oxygen that had already been given for the previous 10 minutes, provides essential information in the initial assessment of infants with suspected congenital heart disease. Accurate anatomical diagnosis, however, depends on the results of cardiac catheterization and angiography.

We are indebted to Dr. G. A. H. Miller who performed cardiac catheterization in many of our patients, and to Dr. R. A. H. Anderson and Elizabeth Thompson for considerable assistance in the preparation of this manuscript.

\section{REFERENCES}

Boston, R. W., Geller, F., and Smith, C. A. (1966). Arterial blood gas tensions and acid base balance in the management of the repiratory distress syndrome. Fournal of Pediatrics, 68, 74.

Brown, R., and Pickering, D. (1974). Persistent transitional circulation. Archives of Disease in Childhood, 49, 883.

Burnell, R. H., Joseph, M. C., and Lees, M. H. (1972). Progressive pulmonary hypertension in newborn infants. American fournal of Diseases of Children, 123, 167.

Campbell, M. (1973). Incidence of cardiac malformations at birth and later, and neonatal mortality. British Heart fournal, 35, 189.

$\star$ Except in the presence of anomalous origin of the right subclavian artery. 
Comroe, J. H., and Botelho, S. (1947). The unreliability of cyanosis in the recognition of arterial anoxemia. American fournal of the Medical Sciences, 214, 1.

Gersony, W. M. (1973). Persistence of the fetal circulation. A commentary. Fournal of Pediatrics, 82, 1103.

Goldman, H. I., Marilat, A., Sun, S., and Lanzkowsky, P. (1973). Neonatal cyanosis and arterial oxygen saturation. fournal of Pediatrics, 82, 319.

Lambert, E. C., Canent, R. V., and Hohn, A. R. (1966). Congenital cardiac anomalies in the newborn. A review of conditions causing death or severe distress in the first month of life. Pediatrics, 37, 343.

Lees, M. H. (1970). Cyanosis of the newborn infant. Fournal of Pediatrics, 77, 484.

Lees, M. H. (1973). Disease of the cardiovascular system. Neonatology, p. 256. Ed, by R. Behrman. Mosby, St. Louis.

Lees, M. H., Way, R. C., and Ross, B. B. (1967). Ventilation and respiratory gas transfer of infants with increased pulmonary blood flow. Pediatrics, 40, 259.

Liebman, J., and Whitman, V. (1973). The heart. Care of the High Risk Neonate. p. 247. Ed. by M. H. Klaus and A. A. Fanaroff. Saunders, Philadelphia.

Miller, G. A. H. (1974). Congenital heart disease in the first week of life. British Heart fournal, 36, 1160.

Nadas, A. S., and Fyler, D. C. (1972). Pediatric Cardiology, 3rd ed., p. 304. Saunders, Philadelphia.

Nelson, N. M., Prod'hom, L. S., Cherry, R. B., Lipsitz, P. J., and Smith, C. A. (1963). Pulmonary function in the newborn infant: the alveolar-arterial oxygen gradient. Fournal of Applied Physiology, 18, 534.

Noonan, J. A., and Nadas, A. S. (1958). The hypoplastic left heart syndrome. Pediatric Clinics of North America, 5, 1029.

Perloff, J. K. (1970). The Clinical Recognition of Congenital Heart Disease, p. 2. Saunders, Philadelphia.

Prec, K. J., and Cassels, D. E. (1952). Oximeter studies in newborn infants during crying. Pediatrics, 9, 756.
Rahimtoola, S. H., Ongley, P. A., and Swan, H. J. C. (1966). The hemodynamics of common (or single) ventricle. Circulation, 34, 14.

Roberton, N. R. C., Hallidie-Smith, K. A., and Davis, J. A. (1967). Severe respiratory distress syndrome mimicking cyanotic heart disease in term babies. Lancet, 2, 1108.

Rowe, R. D., and Mehrizi, A. (1968). The Neonate with Congenital Heart Disease, p. 73. Saunders, Philadelphia.

Shannon, D. C., Lusser, M., Goldblatt, A., and Bunnell, J. B. (1972). The cyanotic infant-heart disease or lung disease ? New England fournal of Medicine, 287, 951.

Strang, L. B., and Macleish, M. H. (1961). Ventilatory failure and right-to-left shunt in newborn infants with respiratory distress. Pediatrics, 28, 17.

Talner, N. S., Sanyal, S. K., Halloran, K. H., Gardner, T. H., and Ordway, N. K. (1965). Congestive heart failure in infancy. I. Abnormalities in blood gases and acid-base equilibrium. Pediatrics, 35, 20.

Tandon, R., Hauck, A. J., and Nadas, A. S. (1963). Persistent truncus arteriosus: a clinical, hemodynamic and autopsy study of nineteen cases. Circulation, 28, 1050.

Tooley, W. H., and Stanger, P. (1972). The blue baby-circulation or ventilation or both? New England fournal of Medicine, 287, 983.

Warley, M. A., and Gairdner, D. (1962). Respiratory distress syndrome of the newborn-principles in treatment. Archives of Disease in Childhood, 37, 455.

Wood, P. H. (1956). Disease of the Heart and Ciculation, 2nd ed., p. 320. Eyre and Spottiswoode, London.

Correspondence to Dr. E. A. Shinebourne, Department of Paediatric Cardiology, Brompton Hospital, Fulham Road, London, SW3 6HP. 